\title{
Seguridade Social no Brasil ${ }^{1}$
}

Tatiana Wargas de Faria Baptista

\section{Introdução}

A seguridade social brasileira, como uma política formulada no contexto de redemocratização do Estado na década de 80 e apresentada institucionalmente na Assembléia Nacional Constituinte de 1987/88, veio responder às demandas de reestruturação da política social no Brasil, contrapondo-se à política de seguro social e política assistencialista desenvolvidas no país até àquela data ${ }^{2}$. A seguridade social produziu um novo ideário social a partir de 1988, que determinou a formulação de uma estrutura de proteção social abrangente (universalidade da cobertura e do atendimento), justa (uniformidade e equivalência dos benefícios e serviços às populações urbanas e rurais), eqüânime (eqüidade na forma de participação do custeio) e democrática (caráter democrático e descentralizado na gestão administrativa), onde o Estado passou a ter a responsabilidade da provisão e o dever de atenção (Brasil, 1988, art.194).

O ideário da seguridade social apresentou semelhanças com o ideário político desenvolvido nos sistemas de proteção social do welfare state europeu ${ }^{3}$, retratando o compromisso do Estado na formulação de políticas mais efetivas na área social e na composição de uma aliança política entre a área econômica e a área social do Estado. A eqüidade, a justiça social e o redistributivismo serviram como princípios de base ao projeto de universalização da proteção social proposto para o Brasil na Constituição Federal de 1988, sendo utilizado pelos grupos reformistas defensores da proposta. Desta forma, a seguridade social integrou-se à proposta de construção de um Estado democrático centrado na idéia de afirmação da cidadania social e não mais de uma "cidadania regulada", tal como especificou Santos (1979) ${ }^{4}$.

Pesquisadora do Instituto de Medicina Social,

Universidade do Estado do Rio de Janeiro IMS/UERJ 
Nesta perspectiva, a seguridade social veio propor também um redesenho institucional do Estado na condução das políticas sociais, com a formulação de um ministério e orçamento únicos para o conjunto dos setores integrantes do sistema de seguridade social: saúde, previdência e assistência social. Este novo setor passaria a ser financiado (direta e indiretamente) por toda a sociedade, através de um único órgão controlador e gestor destes três setores, o Ministério da Seguridade Social (Brasil, 1988, art.194/195).

Contudo, desde 1988 e mais precisamente após a promulgação da "Constituição Democrática", as alianças políticas obtidas no curso da transição democrática - e que possibilitaram o encaminhamento dos projetos reformistas do Estado, discutidos por praticamente uma déca$\mathrm{da}^{5}$ - passaram a sofrer recomposições, o que significou a ocorrência de processos não tão coerentes com o projeto político inscrito na Constituição de 1988. Assim, os que foram negociados para a área social tiveram seus encaminhamentos legais no período pós-constituinte, mas sofreram ainda uma série de entraves políticos, jurídicos, institucionais e outros, dificultando o desenvolvimento das políticas anteriormente acordadas. Como veremos a seguir, as frágeis bases políticas de sustentação dos projetos reformistas no pré-constituinte e Constituinte comprometeram em demasia o desenvolvimento dos mesmos no período pós-constituinte.

$\mathrm{Na}$ atualidade, o projeto da seguridade social não compõe mais uma agenda política de interesse; os grupos políticos anteriormente envolvidos com ele distanciaram-se da discussão político-institucional, e o projeto de reforma (ou contra-reforma) do Estado, presente hoje, aponta para a desintegração dos princípios norteadores da inovadora política protetora, a natimorta seguridade social.

Neste estudo, pretendemos, portanto, enfatizar os pressupostos e acordos políticos que possibilitaram a formulação da seguridade social, desde o período pré-constitucional até seus primeiros encaminhamentos operacionais no pós-constituinte, de modo a relacionar as questões atuais aos principais conflitos enfrentados na operacionalização desta proposta. Pretendemos resgatar os valores e ideais que estiveram presentes no desenvolvimento da proposta de seguridade, a fim de recolocar questões para a política de proteção brasileira atual. Este estudo visa, portanto, apontar perspectivas para a política protetora, refletindo sobre os atuais valores sociais no contexto de reestruturação das políticas de proteção social e reavaliando posturas frente às políticas de privatização e redução do Estado. São estas questões que estarão presentes no corpo desta discussão, que tem como eixo central a discussão do processo de formulação da política protetora da seguridade social nos anos 80 . 


\section{Grupos de discussão}

A primeira questão que devemos discutir na análise da seguridade social brasileira diz respeito à forma como se desenvolveu este projeto político na arena político-institucional de negociação no Brasil e, portanto, quais foram os grupos de interesse presentes nessa discussão.

O debate sobre a proposta da seguridade social teve início e ganhou expressão no âmbito político-institucional do Estado brasileiro no ano de 1986, no contexto do governo da Nova República (1985), mais precisamente nas discussões da Comissão de Reestruturação da Previdência Social (CRPS), que teve por objetivo "realizar estudos e propor medidas para reestruturação das bases de financiamento da previdência social e para reformulação dos planos e benefícios previdenciários" (Brasil, 1986).

Nessa Comissão, um grupo político em particular vocalizou a intenção do projeto da seguridade social, o grupo de "reformistas da previdência social". Este grupo era composto por personagens políticos expressivos da Previdência Social e apresentou uma proposta que condizia com o projeto de reforma idealizado pela direção do Ministério da Previdência e Assistência Social (MPAS) naquele momento.

A concepção de seguridade social apresentada correspondia a uma proposta de universalização da proteção social, com a composição de um efetivo Estado de bem-estar social no Brasil. Esta proposta indicava incluir e organizar saúde, assistência e previdência num mesmo sistema, com novas bases de financiamento e com a inclusão, no sistema, de toda a população residente no Brasil. Assim, a seguridade social vinha constituir uma política de redistribuição e justiça social, dando um sentido gradual à reforma. Para os idealizadores do projeto de bem-estar, a aceitação do conceito de seguridade social só viria facilitar o desenvolvimento político-institucional da reforma no âmbito dos três setores referidos, que tratados em conjunto conquistariam um espaço institucional no Estado bastante expressivo.

Neste contexto, destacaram-se algumas forças políticas resistentes ao encaminhamento da proposta de seguridade social, desde forças políticas mais conservadoras ligadas a outros setores do Estado, como as mais progressistas associadas aos projetos reformistas mais inovadores. Devese considerar, portanto, quatro grupos de interesses contrários ao modelo da seguridade social nesta fase de discussão (1985-1986 - pré-constituinte): um grupo constituído por personagens conservadores da área econômica, política e administrativa do Estado; um formado pela técnico-burocracia previdenciária; outro representado pelos trabalhadores e aposentados e o último composto por reformistas do setor saúde. Cada um desses grupos reunia razões para se opor ao projeto da seguridade, evidenciando a fragilidade inicial desta proposta. 
Para o grupo conservador, o motivo para a resistência ao projeto da seguridade estava na proposta em si, ou seja, no que ela significava em termos de construção política e no que ela exigia de participação e compromisso do Estado e das elites. Afinal, a política de seguridade significava uma política de redistribuição de renda e, como tal, exigia a participação de todas as parcelas sociais no compromisso político com o projeto social. Para os grupos conservadores, essa política mostrou-se, na essência, perigosa. E ainda, com a constituição de um órgão único, gerindo saúde, previdência e assistência, estaria formando-se uma estrutura político-administrativa na área social, fortíssima, frente a outras áreas do Estado. A constituição de um ministério social forte não era exatamente o que vislumbrava o grupo conservador, como projeto de reforma do Estado.

O grupo formado pela técnico-burocracia previdenciária se opôs ao projeto da seguridade social por outras razões. A este grupo interessava o poder institucional já conquistado pela previdência social, que se havia constituído autônoma e forte desde 1974, com a criação do MPAS. Assim, negociar qualquer nível de mudança na capacidade institucional do MPAS, seja dividindo funções, seja reformando organizações, esbarrava com resistências desse grupo.

Já para o grupo constituído por trabalhadores e aposentados a proposta da seguridade social desenhou-se, nessa fase (pré-constituinte), como uma verdadeira ameaça, o que tornou este grupo um importante opositor à proposta da seguridade. O grupo temia que com a formação da seguridade social houvessem perdas reais, tanto financeiras, quanto em benefícios para o grupo. Tinha medo da universalização, porque receava ser o principal pagador do projeto, e da não manutenção da qualidade dos serviços assitenciais prestados à população previdenciária. $\mathrm{Na}$ realidade, esta avaliação negativa e resistente ao projeto da seguridade vinha responder a uma situação real já vivida por este grupo. Com a expansão da cobertura previdenciária e assistencial, desde meados dos anos $70^{6}$, este grupo vinha sentindo a diferença qualitativa nos serviços, que não correspondiam mais às expectativas do mesmo. A partir de então, tornara-se uma constante a crítica à universalização e, portanto, à seguridade social, quando esta foi apresentada na Comissão de Reestruturação da Previdência Social em 1986. Assim, os trabalhadores e aposentados apresentavam-se no debate da Comissão com dois posicionamentos básicos, utilizados como referência também pelos grupos resistentes no interior do MPAS, referindo-se basicamente à política de saúde e ao projeto de universalização nesta área:

a) a assistência à saúde é um dever do Estado, devendo ser suprimida das obrigações da Previdência Social; 
b) o INAMPS, como um patrimônio específico da Previdência Social, uma garantia daqueles que trabalham, não poder ser estendido a toda população, substituindo o papel do Estado (Brasil, CRPS, 1986).

Com estas falas, o grupo dos trabalhadores e aposentados, firmava uma postura corporativa, que tinha como preocupação básica a previdência, propriamente dita, do trabalhador formal. O que este grupo vocalizava era o interesse de uma política protetora meritocrática, financiada pelo trabalhador, empregador e Estado, como já se estabelecia até aquela data. E uma política de proteção seletiva, assistencialista, financiada pelo Estado, para as parcelas da população excluídas do vínculo formal de trabalho. A fala abaixo resume o posicionamento deste grupo:

“... muito bem, muito bonito, avançamos no sentido de dar maior cobertura à população, mas isso está sendo financiado com recursos do assalariado e deve ficar com o previdenciário, e ponto final" (fala de um representante dos aposentados na Comissão. CRPS, 1986, p.583).

$\mathrm{O}$ quarto grupo resistente à proposta da seguridade era formado pelos "reformistas do setor saúde". A polêmica entre "reformistas da saúde" e "reformistas da previdência" contava com especificidades e trazia resistências ao encaminhamento do projeto de bem-estar. Por outro lado, o grupo que mais se aproximava de uma aliança com o projeto da seguridade era o grupo da saúde, pois este, da mesma forma, apresentava como projeto político a proposta de universalização dos serviços e a constituição de um Estado protetor. No entanto, havia entre esses dois grupos uma discordância básica com relação ao encaminhamento da reforma. Esta discordância esteve presente desde o início do debate reformista entre o setor saúde e o previdenciário, em meados da década de 70, e explicitou-se no Governo da Nova República, quando os reformistas passaram a ocupar os lugares de gerência dos ministérios da Saúde e da Previdência e Assistência Social. Para a compreensão desta ambigüidade e todos os seus efeitos maléficos na reforma do sistema, é necessário retomar alguns aspectos desta polêmica.

Os "reformistas da saúde" continham um projeto político integrador do setor saúde, a "reforma sanitária", que vinha sendo amplamente discutida, desde meados dos anos 70, no âmbito institucional do Estado brasileiro $^{7}$. Nele constava, em linhas gerais, da universalização, unificação e integralidade das ações de saúde no Ministério da Saúde (MS), que passaria a gerir toda a política relativa à saúde. Nesta concepção, o novo ministério passaria a incluir desde as ações de caráter curativo, exercidas até aquela data pelo INAMPS/MPAS, até as ações de caráter coletivo, historicamente função do Ministério da Saúde, compondo uma política 
descentralizada de poder, onde cada esfera de comando cumpriria funções políticas específicas. Tratava-se de um projeto setorial da saúde, que visava uma política imediata de implementação da reforma, independente de qualquer vínculo com a Previdência Social. Mas a Previdência ainda era, nesse período, a principal condutora da política de saúde, através do INAMPS. E neste ponto incidia o conflito entre os dois grupos.

Os "reformistas da previdência", presentes no MPAS, compartilhavam das idéias de reforma no tocante à universalização da saúde, mas propunham estratégias para a unificação, que não correspondiam à transferência imediata do INAMPS para a saúde. Como o INAMPS concentrava muito poder institucional e tinha autonomia administrativa em suas ações, a transferência de gestão para o MS significava um pouco mais que a transferência de recursos: significava não só a transferência de poder político como também a perda de autonomia na gestão da política. A proposta apresentada pelos "reformistas da previdência", num primeiro momento (primeiro ano Sarney), foi, então, de "modernização da máquina previdenciária e de promoção e maior eficiência e agilidade ao INAMPS" (Cordeiro, 1991), mantendo-o na estrutura da previdência social.

A diferença fundamental entre os dois setores - saúde e previdência - dizia respeito à maneira como cada um entendia a reforma, refletindo o percurso político-institucional de cada um desses setores ${ }^{8}$. A Previdência Social, como o órgão que controlava a área médicoassistencial da política de saúde, desde 1974, através do INAMPS, concentrava poder institucional e econômico bem mais significativo que o MS, que realizava ações de caráter eminentemente preventivo, desde $1953^{9}$. Esta forma de organização da política de saúde, onde a assistência curativa e as ações preventivas eram administradas por órgãos diferentes, foi o principal motivo da reforma (pelo menos desde meados dos anos 70), promovendo algumas modificações na estrutura organizativa da saúde nos primeiros anos da década de $80^{10}$, não alterando, entretanto, em profundidade, a política de saúde.

Com o advento da Nova República (1985) e a entrada dos reformistas no Ministério da Saúde e no Ministério da Previdência e Assistência Social ${ }^{11}$, intensificaram-se as pressões por modificações imediatas na estrutura da saúde (integração do sistema de saúde). Neste contexto, cada grupo de reformistas apresentou estratégias políticas diferenciadas para seus setores, condizentes com a compreensão do funcionamento e dinâmica dos setores em que estavam inseridos. Explicitava-se a polêmica quanto ao modo de encaminhamento da reforma. Na Nova República, a disputa ideológica sobre a compreensão da reforma deslocou-se para uma disputa de poder, e o conflito maior passou a resumir-se na estratégia de unificação da saúde, com a passagem do INAMPS para o MS. 
Neste contexto, foi apresentada a proposta da seguridade, que surgia inicialmente a partir da direção do MPAS e, logo em seguida, era incorporada pelos demais "reformistas da previdência", presentes especialmente no INAMPS. A proposta da seguridade vinha determinar uma solução para o impasse reformista vivido pelos dois setores, a saúde e a previdência, propondo a integração deles num sistema único de proteção social.

No entanto, os "reformistas da saúde" entenderam a proposta da seguridade mais como uma estratégia política do MPAS para manter o poder centralizado, do que como uma proposta de composição de uma política protetora inovadora na área social. As primeiras reações dos "reformistas da saúde" foram de negação do novo modelo e de afirmação da proposta política de unificação e constituição de um único Ministério da Saúde, autônomo e com fontes de financiamento próprias.

O jogo político que permitiu tanto a apresentação da proposta da seguridade como a sua imediata recusa pelos "reformistas da saúde" esteve marcado pelas disputas de interesse entre os dois grupos. Na realidade, para os "reformistas da saúde", abraçar a proposta da seguridade significava criar novos caminhos para a reforma, onde a saúde não estaria necessariamente à frente. Para os "reformistas da previdência", a seguridade social não desviava a condução da reforma, ao contrário, afirmava uma postura mais potente para o setor, que certamente manteria a previdência na liderança. $O$ projeto da seguridade nascia imerso num jogo de interesses corporativos destes dois setores ${ }^{12}$.

Nesta perspectiva, a proposta de um arcabouço institucional protetor encontrava conflitos em todos os níveis de negociação naquele momento (1986). O ideal de construção de uma sociedade de bem-estar social apresentava-se como um projeto idealizado apenas por um pequeno grupo de reformistas no interior da previdência social, com baixo grau de adesão social, institucional e político.

Desta forma, no período pré-constitucional, o debate acerca da seguridade social era uma questão polêmica e de dífícil consenso. Assim, a primeira conclusão que este estudo indica é a de que não houve, durante o período pré-constitucional, um projeto único e integrador dos três setores que compuseram a seguridade - a saúde, a previdência e a assistência social - o que comprometeu a priori todo o processo de negociação de uma política integrada e compromissada na área social. Esta conclusão permite uma avaliação mais precisa do conceito e modelo de seguridade social definido na Assembléia Nacional Constituinte de 1987/88. A seguridade social, como um projeto, não se apresentou tão consensual como se divulgou, ao contrário, demonstrou a fragilidade dos grupos de interesse e um grande conflito na composição do modelo. Os princípios fundamentais da seguridade social, indispensáveis para o exame da proposta, não foram 
discutidos, e a referência aos Estados de bem-estar social, welfare states

ou Estados protetores, serviu apenas como justificativa nas argumentações gerais para a apresentação da proposta. Na Assembléia Nacional Constituinte e no pós-constituinte, a fragilidade dessas primeiras negociações evidenciou-se, e a indefinição do modelo serviu para uma indefinição política, possibilitando aos grupos de interesse mais conservadores uma flexibilização radical na discussão dos princípios norteadores da proposta de seguridade.

\section{A Assembléia Nacional Constituinte e os princípios gerais da Seguridade Social}

No fórum da Assembléia Nacional Constituinte, os conflitos entre os grupos de interesse permaneceram, e o projeto da seguridade social foi vencido numa primeira fase de discussão dos trabalhos, na subcomissão saúde, seguridade e meio-ambiente. Nesta subcomissão, os "reformistas da saúde" participaram intensivamente, e os relatórios e documentos produzidos na VIII Conferência Nacional de Saúde e Comissão Nacional da Reforma Sanitária ${ }^{13}$ foram utilizados como referência pelos parlamentares. O tema seguridade foi apresentado na subcomissão pelo então ministro da Previdência Social, Raphael de Almeida Magalhães, na perspectiva de uma política integrada entre os três setores sociais, não alcançando, no entanto, inicialmente, o status de um projeto político da subcomissão. Ao término dos trabalhos, o conceito de seguridade foi incluído, referindose apenas à política previdenciária propriamente dita, ampliando somente o conceito de previdência ${ }^{14}$.

Na segunda fase da Constituinte, na Comissão da Ordem Social, os "reformistas da previdência" participaram como consultores do relator (o senador Almir Gabriel) nos trabalhos constitucionais. A partir de então, as negociações passaram a sugerir a incorporação do conceito mais abrangente de seguridade social, incorporando saúde e assistência no modelo antes estritamente previdenciário ${ }^{15}$.

Nesta segunda fase, o projeto da seguridade fortaleceu-se ainda mais, mediante um rearranjo das coligações políticas no fórum constituinte. O quadro de instabilidade política que se desenhava no contexto do Estado brasileiro, e mais especificamente no âmbito da Comissão da Ordem Social, possibilitou um acordo geral entre os grupos progressistas na Comissão. Os grupos conservadores, reunidos no Centrão ${ }^{16}$, tentavam, nessa fase, obstruir o encaminhamento das discussões nas Comissões temáticas, visando impedir que, no tempo regimental, os anteprojetos fossem aprovados. Sem a aprovação dos ante-projetos, a Comissão de Sistematização da Constituinte construiria seus próprios 
projetos, podendo desconsiderar todas as discussões feitas anteriormente.

Foi neste contexto que os grupos progressistas conciliaram a proposta da seguridade social, que foi aprovada e encaminhada para as Comissões finais da Constituinte.

A partir de setembro/outubro de 1987, quando as discussões da Comissão de Sistematização e Plenária Final tiveram início, as forças conservadoras já compunham uma maioria, e o Centrão articulou-se na revisão do regimento interno da Constituinte, alcançando o número necessário de assinaturas para a votação em plenário. O plenário deliberou, por maioria, a mudança do regimento, o que significou que a partir daquele momento (momento final da Constituinte) emendas substitutivas globais poderiam ser apresentadas, possibilitando a mudança das propostas políticas já votadas na Assembléia Nacional Constituinte.

No caso específico da discussão da saúde, da previdência e da seguridade social, a mudança do regimento trazia um clima de instabilidade muito grande, pois as propostas políticas desenhadas para a área social eram muito progressistas, e o Centrão articulava as forças conservadoras da assembléia, revisando todos os tópicos políticos em desacordo com a política geral do grupo.

Assim, a estratégia para a manutenção das propostas progressistas no texto constitucional de 1988 configurou-se nas alianças entre progressistas de facções políticas diferentes e progressistas e conservadores, compondo mecanismos de resistência, como a "fusão de emendas", visando a aprovação em bloco das propostas apresentadas.

Neste contexto, os grupos reformistas aliaram-se mais uma vez na defesa do projeto da seguridade social, esquecendo-se das diferenças estratégicas existentes em cada um dos grupos. No entanto, o próprio grupo conservador do Centrão passou, a partir deste momento, a apoiar a proposta da seguridade social, articulando uma emenda coletiva, apresentando a política protetora. A proposta da seguridade, tal como estava sendo encaminhada, definia um modelo protetor abrangente e flexível, permitindo, tanto para os grupos conservadores quanto para os grupos reformistas, uma posterior rearticulação das políticas e estratégias de implementação do modelo. Os grupos apostavam no processo de negociação que estava por vir; e, para os conservadores, particularmente, o apoio à proposta da seguridade permitia uma margem de manobra maior nas negociações de outras políticas ainda na Constituinte, uma vez que tinham como argumento o fato de haverem "cedido" na área social e que só manteriam seu apoio mediante alianças nas demais áreas.

Assim, ao final das negociações desta última fase, o capítulo referente à seguridade manteve a estrutura de um texto abrangente e sem definições precisas. Os artigos referentes às políticas de saúde, previdência e assistência sofreram alterações nas poucas partes que continham 
definições de estratégias para a operacionalização da reforma. E no caso específico da política de saúde, as novas negociações envolveram a redefinição de algumas propostas do texto previamente votado, tais como: a participação da iniciativa privada, como forma complementar ao Sistema Único de Saúde (SUS); a não definição de um percentual de recursos para a saúde; a não explicitação dos mecanismos de viabilização da descentralização e de unificação do sistema, dentre outras. Os acordos possibilitaram, no entanto e ainda, a manutenção dos princípios básicos da política protetora anteriormente desenhada.

Mas chegava-se nesta fase a um grande consenso, que não definia pactos substantivos nem para o setor saúde, nem para a previdência, nem para a assistência social e muito menos para a seguridade social, o que acabou por criar uma situação de total instabilidade para os setores e suas propostas reformistas. O consenso político neste momento de negociação indicou ser a melhor proposta para os três setores, a integração das políticas na composição de um Ministério único, que reunisse toda a política de assistência social, previdência e saúde. Mas a formulação da seguridade social surgiu, assim, muito mais como uma proposta de resistência e fortalecimento do setor social, num momento de rearranjo político-institucional das forças conservadoras do Estado, do que como um projeto político pactuado a partir dos interesses de cada um desses setores. A seguridade social surgiu fundamentalmente como uma contra-estratégia diante das forças conservadoras do plenário. No entanto, o apoio expressivo dos grupos conservadores a esta proposta demonstrou também a fragilidade política deste modelo que, apesar de ter sido aprovado, foi definido em linhas gerais e imprecisas nos seus princípios elementares. Foi essa a vitória conservadora: acolher um projeto e anulá-lo desde a sua origem.

$\mathrm{O}$ acordo firmado entre os reformistas da saúde, reformistas da previdência, dirigentes do MPAS e parlamentares conservadores e progressistas na definição da seguridade social desenvolveu-se a partir de um projeto sem pacto. Neste conjunto, o setor saúde manteve a garantia da proposta de unificação do setor, com a incorporação do INAMPS ao Ministério da Saúde (MS), e a previdência continuou, até que se estabelecesse novas fontes de custeio, repassando os recursos do INAMPS para o MS. A proposta da seguridade possibilitou, assim, a permanência dos recursos do INAMPS vinculados à previdência, o que era um dos motivos de maior conflito na questão da unificação ${ }^{17}$, e permitiu ao setor saúde a composição do SUS. Para a previdência, a seguridade era um acordo interessante; para o setor saúde, só as medidas legais posteriores poderiam dizer, uma vez que todas as propostas, tanto da saúde quanto da seguridade, dependiam de regulamentação complementar.

O jogo de negociação política, neste período, apontava um conflito explícito entre os grupos de interesse relacionados com os setores saúde e 
previdenciário, e um consenso tático levou à configuração da seguridade

social, mas não à formação de uma base política de sustentação para a proposta. Os grupos políticos apostaram na luta política que estava por vir e na capacidade de negociação de seus quadros no pós-constituinte.

Assim, podemos somar mais duas conclusões no estudo desta política:

1) A Seguridade Social definiu-se na Assembléia Nacional Constituinte; enquanto uma solução para o impasse provocado pelas diferentes propostas de restruturação das políticas de saúde, previdência e assistência social foi precariamente definida, no âmbito de um contexto político marcado pela fragilidade política e baixo nível de consenso acerca da orientação a ser conferida a estas políticas.

2) O grau de generalidade e abstração do texto constitucional de 1988 , no tocante principalmente à política de seguridade social, veio responder às dificuldades de negociação entre os três setores nela inseridos, compondo um texto pouco resistente às mudanças políticas que poderiam vir a se processar no âmbito do Estado brasileiro no pós-constituinte.

A discussão que diferenciava a posição dos "reformistas da previdência" dos "reformistas da saúde" ficou abafada. A proposta da seguridade foi entendida dentro dos pressupostos políticos que interessavam a cada grupo, e nenhuma discussão acerca de seu funcionamento foi desenvolvida.

\section{A explicitação dos dissensos - o pós-Constituinte}

Os anos que se seguiram à Constituição de 1988, principalmente o período compreendido entre 1989 e 1992, evidenciaram a fragilidade e o elevado grau de abstração das negociações políticas, que acabaram por levar à formação, no curso da Assembléia Nacional Constituinte (1987/ 1988), de um consenso sobre a configuração do SUS e do próprio texto constitucional relativo à seguridade social. O prazo de seis meses estabelecido pela Assembléia Nacional Constituinte para a aprovação das leis orgânicas e complementares ao texto constitucional não foi observado, no caso específico da seguridade social. Este fato reflete o grau de dificuldade envolvido na tramitação deste projeto político ao longo dos anos que se seguiram.

Além disso, devemos considerar que as dificuldades ampliaram-se bastante, quando o Congresso Nacional estendeu o governo Sarney por mais um ano de mandato. As dificuldades, a partir de então, passaram a estar referidas a um contexto de grande recomposição dos interesses políticos no país. O ano de 1989, ao tornar-se um ano marcadamente eleitoral $^{18}$, acabou convertendo-se num ano onde as ações institucionais do Estado foram deslocadas para um segundo plano. 
Neste singular contexto político-institucional, diversos grupos políticos tornaram-se solidários ao adiamento da discussão e da aprovação das leis complementares à Constituição. O adiamento desta legislação — que feria claramente os princípios da Assembléia Nacional Constituinte 87/88 — só seria interrompido, quando da nova composição do grupo governista. Todos os grupos políticos consideravam que só após as eleições de novembro de 1989 (para a Presidência, para os governos estaduais e para o Congresso Nacional) se produziria um contexto político mais favorável à discussão dessa legislação complementar, posto que uma nova correlação de forças políticas emergeria das eleições. Assim, caberia ao governo subsequente ao de Sarney promover as bases políticas que possibilitariam converter os princípios da Constituição de 1988 em diretrizes operacionais para as políticas sociais do país.

O debate sobre a composição de um (forte) Ministério da Seguridade Social ao longo do ano de 1989 foi retardado, no âmbito da atuação do MPAS, pelas posturas conservadoras do então ministro da Previdência, Jader Barbalho, e pelo presidente do INAMPS, na ocasião José R.P. Serrão. Afinal, estes dois dirigentes públicos integravam o bloco político liderado pelo Presidente Sarney, que não tinha interesse algum em produzir qualquer mudança de ordem no quadro institucional da Previdência naquele momento.

No entanto, no contexto do MS, prosseguiam as discussões sobre a Lei Orgânica da Saúde (LOS), bem como as pressões para a passagem do INAMPS para o Ministério da Saúde. Na realidade, os reformistas da saúde se articularam na defesa da unificação INAMPS/MS e, sobretudo, pela continuidade do projeto de reforma do sistema de saúde. Promoveram, então, uma reordenação da política do MS centrada no abandono de uma estratégia que privilegiava a construção da Seguridade Social, tal como concebida na Constituição de 1988. Esta postura dos reformistas da saúde marcou um primeiro rompimento do acordo político que presidiu à incorporação do capítulo da seguridade na Constituição de 1988. Este rompimento derivou de uma situação política específica configurada no período: o MPAS e o INAMPS estavam sendo conduzidos por dirigentes compromissados com o bloco político conservador de Sarney e, portanto, desinteressados na efetivação da seguridade social no Brasil, o que dificultava o encaminhamento deste projeto.

O projeto político acordado entre reformistas da saúde, reformistas da previdência, dirigentes do MPAS e parlamentares à época da Assembléia Nacional Constituinte exigiria posteriormente um amplo esforço na composição de uma política integrada MS-MPAS. A composição desta política não teve desdobramentos, pois os reformistas da previdência não encontravam-se mais, a partir de 89 , nos quadros institucionais da Previdência, e não tiveram, portanto, meios de prosseguir no projeto de reforma 
no interior da burocracia previdenciária. Assim, restou aos reformistas da saúde dar prosseguimento ao projeto político de reforma do sistema de saúde de forma autônoma vis-a-vis ao MPAS. A nova composição política dos Ministérios, produzida pelo contexto eleitoral de 1989, não sustentava mais o acordo de uma política integrada MS/MPAS, de modo que a reforma do setor saúde foi conduzida sobre a desintegração do acordo entre estes dois órgãos.

Durante o ano de 1990, os Ministérios foram reorganizados, bem como recompostas as coligações políticas e representações partidárias no Congresso Nacional. O primeiro ano de governo Collor introduziu mudanças nas áreas econômica e institucional do Estado; concentrou e racionalizou atividades, de modo a permitir uma coordenação mais centralizada de todas as áreas ligadas à infra-estrutura e à economia (Fiori, 1992). Não avançou, entretanto, um milímetro sequer, na conformação de qualquer política para a área social, nem na criação de um Ministério único da Seguridade Social, tal como havia sido determinado na Constituição de 1988.

Na realidade, o desprezo do governo Collor face à área social não se resumiu apenas à inoperância das políticas que dariam corpo ao texto constitucional de 1988. Afinal, este governo impôs diversas orientações políticas negativas ao desenvolvimento para o setor social, tal como a Lei 8028 de 12 de abril de 1990. Esta lei apresentada apenas 27 dias após a passagem do governo - de Sarney para Collor — determinou a (re)vinculação do Ministério da Previdência Social (MPAS) ao Ministério do Trabalho, compondo, assim, um Ministério do Trabalho e Previdência Social (MTPS) e um Ministério da Assistência Social totalmente independentes entre si. "Esta lei marcou, portanto, o desmonte definitivo do modelo de proteção social fundado na concepção de Seguridade Social incorporada na Constituição de 1988" (Carbone, 1994). E mais, a aprovação desta lei acabou por revelar a imensa fragilidade dos consensos políticos firmados no curso da Assembléia Nacional Constituinte, ou seja, no período 1987/1988.

Nesta análise, e apenas utilizando este fato como exemplo, podemos afirmar que as mudanças político-institucionais do Estado brasileiro, nos anos 90, foram suficientes para o desmonte de todas as alianças e consensos firmados na Constituição de 1988, em torno da política de seguridade social. Estas mudanças ocorreram de forma acelerada, a partir do ano de 1990, e demonstraram tanto o elevado nível de abstração como a imensa fragilidade das propostas políticas articuladas na Assembléia Nacional Constituinte. Afinal, as alianças políticas não foram capazes de sustentar nem o cumprimento do que já estava escrito em lei, muito menos o que estava previsto ser definido em legislação complementar.

A partir de 1990, a trajetória dos três setores componentes da seguridade começa a diferenciar-se, e a previdência social, que havia mantido a responsabilidade na gestão dos recursos da seguridade, assume um 
papel expressivo na política de desmonte do modelo protetor. A previdência social a partir deste ano (1990), revinculada ao Ministério do Trabalho, passa a disputar os recursos, já escassos ${ }^{19}$, com os demais setores da seguridade. Neste ano também, começam as críticas, por parte da previdência, ao modelo da seguridade social, indicando principalmente a inviabilidade financeira para a sustentação do modelo. Mais um fator contribuiu para o escasseamento dos recursos do Orçamento da Seguridade Social: a entrada dos encargos previdenciários da União (EPU), responsabilidade do Tesouro no Orçamento da Seguridade. O EPU retirou, em média, $20 \%$ do orçamento da seguridade social a partir de 1990 , o que significou que os demais setores da seguridade tiveram $20 \%$ a menos de recursos. A passagem do EPU para o Orçamento da Seguridade Social revelou-se como mais uma manobra política do Governo Collor, dentre outras, no privilegiamento da área econômica frente à área social. A área econômica, com a saída do EPU do Orçamento do Tesouro e a manutenção das fontes de receita, ganhou flexibilidade financeira, diminuiu despesas, aumentou receita.

Em 1992, o dilema da composição da seguridade social explicitavase no Relatório da Comissão do Sistema Previdenciário (Relatório Brito), que assumia a falência do modelo e defendia a separação imediata dos três setores, naquilo que ainda (e somente) os vinculava, o Orçamento da Seguridade Social. Propunha a divisão dos recursos da seguridade, com a especialização das fontes e a vinculação à previdência dos recursos das contribuições sobre a folha. Em 1993, com a reforma constitucional, foi aprovada tal medida, e a saúde passou a contar desde então com os recursos instáveis das demais fontes do orçamento ${ }^{20}$.

Assim, o desmonte da política de seguridade a partir de 1990 baseou-se essencialmente nas fragilidades presentes no texto constitucional de 1988, quais sejam: as estratégias de cooperação e integração entre os setores e a política de financiamento da seguridade. A estratégia política nos anos 90 foi não permitir o pacto da área social e promover a crise entre os setores, não repassando os recursos. No período 90-93, as disputas por recursos acirraram as negociações entre saúde, previdência e assistência, criando impasses de financiamento principalmente na saúde e na assistência. Tudo isso só foi possível mediante as distorções presentes na discussão orçamentária na Constituição de 1988, que se resumem:

a) a política de seguridade social não teve uma distinção dos recursos quanto às diferentes destinações - para a saúde, previdência e assistência — deixando em aberto a discussão do financiamento em cada um destes setores. Esta indefinição revelou-se, nos anos 90, desfavorável às políticas de saúde e política assistencial, que se viram submetidas às regras estabelecidas pela Previdência Social; 
b) o conceito amplo de seguridade social permitiu que outros ministérios e outras despesas orçamentárias, por tradição financiadas pela União, tivessem o financiamento da seguridade social, como o EPU;

c) a partir de 1990 , os recursos complementares a serem transferidos do Orçamento da União tornaram-se irregulares e de pouca expressão. A criação de um Orçamento da Seguridade Social possibilitou o descompromisso da União no financiamento das políticas sociais, criando uma disputa entre os setores da seguridade por mais recursos.

\section{Considerações Finais}

A avaliação final deste estudo indica que as negociações políticas, tanto no âmbito da Assembléia Nacional Constituinte quanto no contexto do Estado, estiveram mais compromissadas com os interesses particulares dos setores técnicos (progressistas ou conservadores) envolvidos no debate da reforma do Estado, do que com os interesses sociais que ali se inseriram. Ou seja, o projeto da Seguridade Social delimitou-se como um exemplo nítido de uma política que se construiu não sobre bases sociais, mas sobre bases técnicas. Os atores fundamentais deste processo de reforma não foram convocados a dramatizar a agenda de ganhos e perdas de processos ou arranjos redistributivos, comprometendo toda a política de reforma ${ }^{21}$.

Nesta perspectiva, a formulação de uma política de proteção social de pretensões welfarianas no Brasil exigia não só a participação da área econômica no projeto social, como um compromisso das elites, governo e trabalhadores, com um projeto de redistribuição social. No entanto, no Brasil, a relação entre a área econômica e a área social manteve-se distante, e os pactos entre os grupos de interesses mostraram-se fragilizados desde a elaboração do projeto de seguridade social até o momento posterior de operacionalização da reforma, o que feriu desde a origem o princípio político do modelo protetor.

Assim, o debate sobre os princípios do welfare foi abrangente e frágil politicamente, e a discussão sobre a política social no Brasil manteve-se como uma discussão independente e setorial, não conquistando o apoio político-institucional necessário à sua operacionalização.

No (des)acordo da seguridade social e nos efeitos perversos que se reproduziram nos anos 90, foram criados novos consensos: a saúde pública é ineficaz, a previdência social é deficitária, a iniciativa privada é a solução. Os novos consensos apontam uma realidade que parece não ter mais volta, uma realidade econômica de poucas possibilidades. Assim, os dilemas da proteção social no Brasil resumem-se hoje em contrapor esta nova realidade aos ideais de construção de uma política de proteção social 
universal e redistributiva, onde as alianças sociais sejam mais do que re-

presentações técnicas ou setoriais de parcelas restritas da sociedade. Para alcançarmos mudanças qualitativas e comprometidas com o pressuposto da solidariedade social, é preciso mais do que alianças políticas "consensuais", como as obtidas com o projeto da seguridade social, ou posturas corporativas (setoriais) e distantes das alianças sociais, como as que se desenvolveram no pós-constituinte. Voltamos agora às perguntas sugeridas na introdução deste artigo: que valores defendemos no contexto de reestruturação das políticas de proteção social? Quais são as alternativas que nos colocamos ao pensar sobre política pública no Brasil?

Sem resposta para estas perguntas, o caminho de discussão de uma política protetora é no mínimo tortuoso. Quando então nos detemos a discutir a saúde, a previdência, o financiamento, os municípios, a disputa por recursos ..., apenas reforçamos uma postura que não pensa a política pública, mas a política setorial. E o velho ditado: "farinha pouca, meu pirão primeiro", aplica-se com a naturalidade de uma realidade. Mas qual realidade mesmo?!

\section{Notas}

1 O título completo deste artigo é: Seguridade Social no Brasil: Uma discussão sobre as micro relações político-institucionais na definição do modelo de proteção social brasileiro. O mesmo corresponde à discussão resumida do trabalho de pesquisa relativo à dissertação de mestrado de Tatiana Wargas de Faria Baptista, desenvolvida no Instituto de Medicina Social da Universidade do Estado do Rio de Janeiro IMS/UERJ, sob a orientação do professor George E.M. Kornis, com o financiamento da CAPES/ENAP no Programa de Apoio à Pesquisa (PAP).

2 Sobre a discussão do modelo de proteção social brasileiro ver Draibe, S. (1989), Draibe, S., Viana, AL. e Silva, P. (1989), Abranches, S. et alli. (1987) e Teixeira, S.M.F. e Oliveira, J. (1986).

3 O welfare state europeu foi constituído nos anos 40, após a Segunda Guerra Mundial, visando a reconstrução econômica, moral e política dos Estados-nação europeus, destruídos pela guerra e fragilizados pela divulgação das idéias de caráter fascista e bolchevista. O welfare state veio propor a construção, via aparelho de Estado, de uma política de promoção do pleno emprego e de um padrão minímo de proteção social à população. Previu a construção de políticas sociais que visassem a justiça social, a redistribuição de renda e a difusão dos princípios de solidariedade e universalismo. Os welfare states promoveram uma articulação específica entre a política econômica e a política social. Para esta discussão ver Esping-Andersen, G. (1994).

4 O estudo de Wanderley Guilherme dos Santos (1979), intitulado Cidadania e Justiça A política social na ordem brasileira, analisa o processo de construção da legislação e 
política social brasileira no período compreendido entre a República Velha e o governo autoritário nos anos 60/70. Classifica o modelo de cidadania brasileiro, como um modelo fundado na relação reguladora do Estado e no vínculo formal de produção do trabalho. O estudo aponta para a formação de uma "cidadania regulada" vinculada aos interesses primeiros das elites e dos governantes do Estado, onde apenas é considerado cidadão aquele que "se encontra localizado em qualquer uma das ocupações reconhecidas e definidas em lei. (...) A cidadania está embutida na profissão, e os direitos do cidadão restringem-se aos direitos do lugar que ocupa no processo produtivo, tal como reconhecido por lei. Tornam-se pré-cidadãos, assim, todos aqueles cuja ocupação a lei desconhece" (p.68).

5 A cronologia que optamos começa no ano de 1979, quando o debate político-institucional na área social tornou-se mais participativo. Neste ano também ocorreram as eleições diretas para os estados e municípios, e a abertura política seguia o seu curso "lento, gradual e seguro". A “transição democrática” tem seu marco inicial também a partir deste ano. Para uma discussão histórica do período ver Skidmore, T.H. (1988); para uma discussão político-institucional do período ver Lessa, R. (1989) e Werneck Viana, L. (1989).

6 Desde o início da década de 70, um movimento de incorporação progressivo dos trabalhadores não-formais processou-se no sistema previdenciário brasileiro, indicando uma forte tendência universalizante do Estado, no tocante às políticas de proteção social: em 1971, com a criação do PRORURAL/FUNRURAL, em 1972, com a incorporação dos empregados domésticos ao INPS e, em 1973, com a regulamentação da filiação dos autônomos. Na área da saúde também foram desenvolvidos programas de universalização gradativa, como o Plano de Pronta Ação (PPA), o Programa de Interiorização das Ações de Saúde e Saneamento (PIASS) e outros mais. Ver Werneck Vianna (1994) e Vater (1996).

7 Para a discussão sobre as propostas e características do movimento de "reforma sanitária" ver Escorel, S. (1987). Para a discussão sobre os conflitos da reforma ver Pereira Filho, C. (1994) e Faria, T.W. (1997).

8 O setor da Assistência Social não constituía um grupo de interesse específico neste momento; integrava-se pois no debate com a Previdência Social, estando inclusive em sua estrutura administrativa.

9 O Ministério da Saúde foi criado no ano de 1953, mas desde o início do século (ou mesmo antes) foram implementadas ações de caráter preventivo em saúde, desde campanhas sanitárias, práticas de saneamento até o controle do espaço urbano e controle das doenças. O Estado assumia desde então um papel específico na área da saúde coletiva, o que era coordenado pelos Departamentos de Saúde Pública, de Higiene e outros. O setor saúde passou a estar na estrutura ministerial apenas nos anos 40, mas ainda dividindo o Ministério com outro setor, a Educação.

10 No ano de 1979, foi realizada a VII Conferência Nacional de Saúde, que propôs a promoção de uma política de saúde que constava da intensificação das ações básicas de saúde para todo o país, o PREV-SAÚDE. Este programa contou com o apoio explícito dos principais grupos de interesse na discussão de saúde, mas não foi implementado institucionalmente. Nos primeiros anos da década de 80, a Previdência Social incorporou no Plano de Reorientação da Assistência Médica da Previdência Social (Plano CONASP) alguns princípios do que foi discutido com o PREV-SAÚDE, desenhando políticas de caráter mais abrangente, universalista e descentralizador, mas não incorporando as medidas de unificação da saúde. Neste período, o conflito entre saúde e previdência, no tocante ao encaminhamento da reforma, já estava presente, mas pouco evidenciado. Os grupos reformistas advindos da saúde entendiam que a reforma pela saúde não avançava mais, porque politicamente não havia um 
quadro favorável. Assim, o conflito interno do grupo reformista não estava explicitado, mas já havia neste período uma diferença fundamental entre os reformistas, da saúde e da previdência, no tocante às estratégias de reforma. Ver Cordeiro, H. (1991).

11 No Ministério da Saúde, Eleutério Rodrigues Neto ocupou o cargo de secretário geral e foi um dos principais personagens do movimento sanitário. Na presidência da FIOCRUZ também outro personagem expressivo do movimento, Antônio Sérgio Arouca. Na presidência do INAMPS, Hésio Cordeiro, também advindo do movimento reformista pela saúde.

12 Ambos os grupos, reformistas da saúde ou da previdência, tinham razões para defender suas estratégias de reforma. A "reforma pelo alto", como ficou conhecida a reforma proposta pelos "reformistas da saúde", vislumbrava o fortalecimento do setor saúde com uma política setorial independente e autônoma. Os "reformistas da saúde" buscavam assumir um poder que estava fragmentado no interior da previdência e da saúde, visavam a socialização de um direito, independente de qualquer vínculo formal de contribuição. A "reforma por baixo", como se designou a reforma proposta pelos "reformistas da previdência", visava um rearranjo de poder gradativo a partir da estrutura previdenciária. Estes entendiam a reforma como um processo gradual de negociação.

13 O relatório da VIII Conferência Nacional de Saúde, realizada em 1986, e os documentos da Comissão Nacional da Reforma Sanitária (1986) expressavam as diretrizes políticas do projeto de reforma proposto pelos "reformistas da saúde". A utilização deste material como textos-base na discussão da Assembléia Nacional Constituinte relatou o interesse em divulgar amplamente as idéias apresentadas por este grupo.

14 Os trabalhos constitucionais foram divididos em quatro fases operacionais. A primeira fase com as discussões nas subcomissões temáticas (neste caso: subcomissão saúde, seguridade e meio-ambiente). A segunda, com a reunião das subcomissões em uma única comissão (Comissão da Ordem Social). A terceira fase de sistematização de um texto final, com a reunião de todas as Comissões. E finalmente a última, com a Plenária Final e a votação definitiva do texto constitucional. No entanto, numa análise mais específica deste processo, deve-se considerar a forma de encaminhamento de toda a discussão, num contexto de mudanças políticas mais gerais processadas no Estado. Assim, podemos dividir o período constituinte em duas fases: o período de trabalho das subcomissões, quando a aliança política entre governo-forças progressistas e forças conservadoras ainda mantinha-se consistente (Aliança Democrática); e o período de discussão das Comissões, Comissão de Sistematização e Plenária Final, que coincidiu com a reviravolta conservadora da aliança democrática.

15 Para a discussão sobre a Assembléia Nacional Constituinte ver Brasil (1987/1988), Carbone, C. (1994) e Faria, T.W. (1997).

16 O Centrão foi um grupo que se constituiu no interior do Congresso Nacional e Assembléia Nacional Constituinte na segunda metade do Governo Sarney. Este grupo reuniu $35 \%$ de representação parlamentar e foi composto essencialmente por integrantes dos partidos conservadores, como PFL, PDS e outros. O Centrão se articulou para a defesa de propostas políticas de cunho conservador. Uma das primeiras discussões encabeçadas por este grupo esteve relacionada à mudança do regimento interno da Constituinte, visando modificar as regras do jogo no tocante à apresentação de emendas e substitutivos ao texto constitucional.

17 A passagem dos recursos do INAMPS para o MS era um dos principais motivos de conflito com os dirigentes do MPAS e burocracia do MPAS de um modo geral. O maior conflito da unificação com os "reformistas da previdência" era sobretudo estratégico: estes entendiam que a saída do INAMPS do MPAS significava justamente a perda de recursos e poder político deste órgão. Assim, a passagem do INAMPS para o MS no 
contexto da seguridade visava evitar a perda financeira do INAMPS frente à Previdência. Mas as negociações na Assembléia Nacional Constituinte deixaram em aberto a discussão do financiamento, e a Previdência manteve o controle de todos os recursos, inclusive aqueles antes repassados ao INAMPS.

18 No ano de 1989, realizaram-se as eleições para a Presidência da República e para governadores de estado. No ano de 1990, realizaram-se as eleições para deputados e senadores.

19 A partir de 1990, a política de repasse de recursos implementada pela União prejudicou o Orçamento da Seguridade Social. O repasse dos recursos chegava com meses de atraso sem qualquer tipo de correção, o que em tempos de alta inflação (em 1990 foi de $1476,6 \%$ ) constituía uma perda orçamentária brutal. Neste contexto, os setores mais prejudicados da seguridade social eram saúde e assistência, que podiam flexibilizar seus orçamentos no corte de despesas "excessivas". Desde então a disputa de recursos entre saúde, previdência e assistência tornou-se uma constante.

20 As demais fontes de financiamento da Seguridade Social são: recursos ordinários do Tesouro, títulos do tesouro e operações de crédito, receitas próprias, contribuição sobre o lucro, FINSOCIAL/COFINS, fundo social de emergência e outros.

21 Para Costa (1994) esta análise também explica porque os sindicatos passaram a incorporar em suas agendas políticas o direito ao seguro saúde privado. Os sindicatos e os trabalhadores, de um modo geral, não incorporaram a política de proteção como uma agenda política de interesse. A história política dos sindicatos no Brasil montou-se sob bases corporativas bastante diferentes de outros países; o corporativismo classista brasileiro destruiu (e ainda destrói) alianças para uma política social abrangente. Nos países do $W S$, o corporativismo, ao contrário, possibilitou alianças sociais e criou agendas políticas de interesse que serviram como mecanismo de pressão sob os governos. O WS teve uma base social sólida e ainda hoje resiste às reformas liberais por conta da base político-social de sustentação deste projeto. Ver também Werneck Vianna (1997).

\section{Referências Bibliográficas}

Abranches, S.H. et alli. (1987), Política Social e Combate à Pobreza. Rio de Janeiro, Jorge Zahar.

BRASIL. MPAS. (1986), Rumos da Nova Previdência. Anais do grupo de trabalho para reestruturação da previdência social. Brasília.

BRASIL. Senado Federal. (1987/1988), Atas da Assembléia Nacional Constituinte.

BRASIL. Presidência da República. (1988), Constituição da República Federativa do Brasil. Brasília.

Carbone, Célia O. (1994), Seguridade Social no Brasil. Ficção ou Realidade?. SP: Editora Atlas.

Cordeiro, H. (1991), Sistema Único de Saúde. Rio de Janeiro. Ayuri Editorial.

CosTA, N. (1994), Inovação Institucional, distributivismo e crise: a política de saúde nas décadas de 80 e 90. Rio de Janeiro: ENSP/FIOCRUZ (mimeo).

DaIN, Sulamis (1994), Financiamento da Seguridade Social, in A Previdência Social e a Revisão Constitucional. Brasília, Convênio MPS/CEPAL. 
Draibe, S.M. (1989), O Welfare State no Brasil: características e perspectivas, in Ciências Sociais Hoje, ANPOCS.

Draibe, S.M.; Viana, AL.; Silva, P.L.B. (1989), Desenvolvimento de Políticas de Saúde nos anos 80. O caso brasileiro. Acordo Técnico NEPP/UNICAMP/Organização PanAmericana de Saúde. São Paulo.

EsCOReL, S. (1987), Reviravolta na saúde; origem e articulação do movimento sanitário. Dissertação de Mestrado. Rio de Janeiro. DAPS/FIOCRUZ/ENSP

Esping-Andersen, G. (1994), O Futuro do Welfare State na Nova Ordem Mundial. Revista Lua Nova, n.33.

FARIA, Tatiana Wargas. (1997), Da Utopia à Realidade. Dilemas e Consensos na definição da Seguridade Social Brasileira na Constituição de 1988. Série Estudos em Saúde Coletiva. Rio de Janeiro: MS/UERJ.

FiORI, J.L. (1992), O Desafio Político-Econômico Brasileiro no contexto LatinoAmericano. Série Estudos em Saúde Coletiva. Rio de Janeiro: IMS/UERJ. n. 13.

Lessa, Renato. (1989), Fados de um Republicídio, in Camargo, A. ; Diniz, E. (org.) Continuidade e Mudança no Brasil da Nova República. Iuperj, Vértice, Rio de Janeiro, São Paulo.

Pereira Filho, Carlos. (1994), A Política Pública como Caixa de Pandora: organização de interesses, processo decisório e efeitos perversos na reforma sanitária brasileira 1985/1989. Dissertação de mestrado em Sociologia pela Universidade Federal de Pernambuco.

SAntos, W. G.(1979), Cidadania e Justiça. A política social na ordem brasileira. Rio de Janeiro. Editora Campus, 3ª edição, Ano 1994.

SKIDIMORE, T. (1988), Brasil: De Castelo a Tancredo, 1964-1985. Rio de Janeiro. Paz e Terra

Teixeira, S.M.F. \& Oliveira, J.A. (1989), (Im) Previdência Social. Petrópolis, Vozes.

VATER, M.C. (1996), A Política Social no Governo Geisel. Rio de Janeiro, IMS/UERJ, Dissertação de Mestrado.

Werneck Vianna, L.(1989), A Transição: da Constituinte à Sucessão Presidencial. Rio de Janeiro: Revan

Werneck Vianna, Maria L.T. (1994), A Seguridade Social no Brasil no Contexto das Políticas Públicas. Programa de Capacitação em Seguridade Social. Rio de Janeiro, IMS/UERJ, DATAPREV, MPS.

. (1997), Política versus Economia: notas (menos pessimistas) sobre globalização e Estado de Bem-Estar, in Gerschman, S. \& Werneck Vianna, M.L.T. (1997) A Miragem da Pós-modernidade. Democracia e políticas sociais no contexto da globalização. Rio de Janeiro: FIOCRUZ. 


\section{Seguridade Social no Brasil}

Este artigo analisa a política de seguridade social brasileira na perspectiva de sua formulação legal na Carta Constitucional de 1988, com o objetivo de discutir três enfoques relativos a esta política: os grupos de interesse implicados no projeto da seguridade social na Assembléia Nacional Constituinte de 1987/88; os princípios político-ideológicos que nortearam a definição deste modelo protetor; e os obstáculos surgirdos na elaboração e operacionalização desta proposta. Passados nove anos da promulgação da "Constituição Democrática", os princípios norteadores da Seguridade Social ainda não foram implementados, e os três setores nela inseridos — saúde, assistência e previdência social - deram prosseguimento à elaboração de políticas setorializadas e independentes. Este artigo discute, assim, as perspectivas da política protetora brasileira, utilizando como referência o debate histórico de formulação desta política e apresentando os principais impasses no desenvolvimento da política protetora.

\section{Seguridad Social en Brasil}

\section{Tatiana Wargas de Faria Baptista}

Este artículo analiza la política de la seguridad social brasileña, desde la perspectiva de su formulación legal en la Carta Constitucional Brasileña del año 1988, con el objetivo de debatir sobre tres enfoques relativos a ésa: qué grupos de interés han estado involucrados en el proyecto de la seguridad social en la Asamblea Nacional Constituyente del año 1987/88, qué principios político-ideológicos han orientado la definición de ese modelo protector y qué obstáculos han surgido a la elaboración y operacionalización de esa propuesta.

Después de haber pasado nueve años de la promulgación de la "Constituición Democrática", los principios que han originado la elaboración del proyecto de la Seguridad Social, aún no habían sido ejecutados y los tres sectores en ella insertados - la salud, la asistencia y la seguridad social — han dado proseguimiento a la elaboración de políticas por sectores e independientes.

Este artículo teoriza las perspectivas de la política protectora brasileña, utilizando como referencia la contienda histórica de la formulación de esa política y presenta las principales dificultades para la realización y desarrollo de la política protectora.

\section{Social Secutiy in Brasil}

\section{Tatiana Wargas de Faria Baptista}

This article analyses how the institutional reform process had taken place in Brazil since the late eighties and how the Social Security policy was built in the Brazilian's Constitution in 1988. This article analyses: which groups had acted in the building of the social policy in the Constitutional Assembly in 1987/88; which principles defined the social policy and which obstacles caused problems in the development of this policy. After nine years the social security hasn't been carried out and the innovations of the Brazilian's Constitution haven't been effective. The three areas inserted in the security system together and developed their policies by themselves. Then, this article discusses the perspectives of the Brazilian protective policy showing the main problems that have been occuring in the development of this policy.

Pesquisadora do Instituto de Medicina Social, Universidade do Estado do Rio de Janeiro IMS/UERJ 